\title{
ROLE OF MAGNESIUM SULPHATE IN NEWBORNS WITH BIRTH ASPHYXIA.
}

\author{
DR. HAFIZ MUHAMMAD IJAZ AHMAD, MBBS \\ DHQ TEACHING HOSPITAL, SAHIWAL, PAKISTAN.
}

DR. SAQIB ALI, MBBS

DHQ TEACHING HOSPITAL, SAHIWAL, PAKISTAN.

\section{DR. GULRAIZ IQBAL, MBBS}

\author{
CIVIL MEDICAL OFFICER, THQ, HOSPITAL, KAIL NEELAM, AZAD JAMMU AND KASHMIR, \\ PAKISTAN.
}

\begin{abstract}
;
Background; Birth asphyxia is a leading cause of mortality and morbidity in neonates in developing countries, with an incidence of 100-250/1000 live births compared to 5-10/1000 live births in the developed world. It remains a significant cause of loss of life and adverse developmental outcome. Objective; To compare magnesium sulphate therapy versus placebo in control of fits among newborns admitted with birth asphyxia along with fits at a tertiary care hospital. Material and Methods; All the study $(\mathrm{n}=260)$ participants of either sex who met inclusion of this study were who are admitted with birth asphyxia. Group A was study group and was treated with magnesium sulfate in a dose of $250 \mathrm{mg} / \mathrm{kg}$ initially within six hours of birth followed by $250 \mathrm{mg} / \mathrm{kg}$ at 24 and $48 \mathrm{~h}$ of birth while group B (control group) was not given MgSO4 therapy and were observed for control of fits and was given standard treatment. Results; Of these 260 study cases, 139 (53.5\%) were male patients while $121(46.5 \%)$ were female patients. Mean age of our study cases was $3.84 \pm 1.47$ hours. Of these 260 study cases, $177(68.1 \%)$ belonged to rural areas and $83(31.9 \%)$ belonged to urban areas. Of these 260 study cases, home delivery was noted in $91(35.0 \%), 149(57.3 \%)$ in private clinics / hospital and $20(7.7 \%)$ in teaching hospital. Mean gestational age of our study cases was $38.23 \pm 2.38$ and preterm births were noted in 91 (35.0\%) of our study cases. Of these 260 study cases, control of fits were noted in $173(66.5 \%)$ while control of fits in group A were noted in $105(80.8 \%)$ and in group B it was $68(52.3 \%)(\mathrm{p}=0.000)$. Conclusion; Our study results support the use of Magnesium Sulphate in control of fits in children with birth asphyxia. Magnesium sulphate was safe, reliable and having no side effect so it can be used safely in these patients to reduce morbidity and mortality. All clinicians treating such patients can employ this treatment modality having safety and efficacy.
\end{abstract}

Keywords; Birth asphyxia, Control of fits, Magnesium Sulphate.

DOI: $10.7176 / \mathrm{JMPB} / 54-20$

Publication date: April $30^{\text {th }} 2019$

\section{INTRODUCTION:}

Birth asphyxia is an insult to the fetus or newborn due to failure to breath or breathing poorly, leads to decrease oxygen perfusion to various organs ${ }^{1}$. Birth asphyxia is a leading cause of mortality and morbidity in neonates in developing countries, with an incidence of 100-250/1000 live births compared to 5-10/1000 live births in the developed world. It remains a significant cause of loss of life and adverse developmental outcome ${ }^{2-4}$. The major causes of neonatal deaths globally were estimated to be infections (35\%), preterm births (28\%) and birth asphyxia (23\%). As large number of deliveries in the developing world takes place at home, there is no reliable data to precisely estimate the disease burden in countries like Pakistan. However, this figure is likely to be very high as two thirds of world's neonatal mortality occurs in 10 developing countries. In Pakistan, over 5 million children are born each year. Of them 0.45 million die before first birthday and nearly half of these deaths occur 
during the neonatal period ${ }^{5,6}$. In 2001, birth asphyxia was responsible for $35 \%, 14 \%$ and $11 \%$ of neonatal mortality in Lahore, Karachi and Khyber Pukhtunkhwa respectively ${ }^{6,7}$.

Asphyxia leads to two types of cerebral insults: the primary neuronal injury that occurs at the time of the hypoxic-ischemic insult and the secondary neuronal injury that occurs over hours to even days following the accumulation of excessive intraneuronal calcium as a result of excitatory amino acid stimulation of the $\mathrm{N}$ methyl-D-aspartate (NMDA) cell receptors ${ }^{8,9}$. It has been shown that NMDA receptor antagonists block calcium ion entry and preserve neuronal function and structure. MK 801, a NMDA receptor antagonist, has been shown to be neuroprotective in immature animals with asphyxia, but is too toxic to be evaluated in the human neonate. Magnesium ion gates the NMDA channels in a voltage-dependent manner and may protect the brain from NMDA receptor-mediated injury ${ }^{10}$. A study from Sri Lanka ${ }^{11}$ has reported MgSO4 was effective in controlling of fits as fits, continued at 24 hours in $18.5 \%$ in treated neonates having birth asyphyxia while control group (without MgSO4) exhibited more fits $34.4 \%$.

The results will help us to offer this treatment modality to our patients which will decrease disease related morbidity and mortality. The results will help suffering families in relieving certain financial and psychological stress.

\section{Material and Methods;}

All the study $(n=260)$ participants of either sex who meet inclusion of this study were enrolled from department of Pediatric medicine, DHQ Teaching hospital Sahiwal, Pakistan who were admitted with birth asphyxia. Patients with congenital heart diseases (ventricular septal defect, transposition of great arteries seen on echocardiography, multiple congenital anomalies like Down Syndrome (determined by physical examination) were excluded from our study. Patients were randomly divided in 2 groups (by draws method). Group A was study group and was treated with magnesium sulfate in a dose of $250 \mathrm{mg} / \mathrm{kg}$ initially within six hours of birth followed by $250 \mathrm{mg} / \mathrm{kg}$ at 24 and $48 \mathrm{~h}$ of birth while group B (control group) was not given MgSO4 therapy and were observed for control of fits and was given standard treatment as per hospital protocols. Age, gender, residential status and place of delivery were taken and noted in the proforma. The diagnosis was done by a senior pediatrician having 5 years experience after fellowship in pediatric medicine. All the data was entered and analyzed using SPSS-20. Descriptive statistics was applied to calculate mean and standard deviation for age in hours. Frequencies and percentage were calculated for the categorical variables like gender of children, monthly family income, control of fits, place of delivery and residential status (Rural/Urban). Control of Fits was compared in both by applying chi-square test at level of significance of 0.05 .

\section{$\underline{\text { RESULTS; }}$}

Our study comprised of a total of 260 patients meeting inclusion criteria of our study. Of these 260 study cases, $139(53.5 \%)$ were male patients while $121(46.5 \%)$ were female patients. Mean age of our study cases was 3.84 \pm 1.47 hours (with minimum age of our study cases was 1 hour while maximum age was 6 hours). Mean age of the male patients was noted to be $3.61 \pm 1.03$ hours while that female patients was $2.96 \pm 1.28$ hours $(p=0.531)$. Our study results have indicated that majority of our study cases i.e. $165(63.5 \%)$ were aged up to 3 hours. Of these 260 study cases, $177(68.1 \%)$ belonged to rural areas and $83(31.9 \%)$ belonged to urban areas. Monthly family income up to Rs. 35000 was noted in 151 (58.1\%) and more than Rs. 35000 was noted in $109(41.9 \%)$ in our study cases. Of these 260 study cases, home delivery was noted in $91(35.0 \%), 149(57.3 \%)$ in private clinics / hospital and $20(7.7 \%)$ in teaching hospital. Vaginal deliveries were noted $179(68.8 \%)$ while cesarean section deliveries were noted in $81(31.2 \%)$. Mean gestational age of our study cases was $38.23 \pm 2.38$ and preterm births were noted in $91(35.0 \%)$ of our study cases. Of these 260 study cases, control of fits were noted in 173 $(66.5 \%)$ while control of fits in group A control of fits were noted in $105(80.8 \%)$ and in group B it was 68 $(52.3 \%)(\mathrm{p}=0.000)$.

\section{DISCUSSION;}

Asphyxia remains a common problem in neonatal units and is a significant cause of morbidity and death in term and preterm neonates. The incidence of asphyxia is estimated to be between 1 and 8 per 1000 live births. This wide range can be largely attributed to problems in selecting indicators to identify children with perinatal asphyxia $^{12,13}$. 
Our study comprised of a total of 260 patients meeting inclusion criteria of our study. Of these 260 study cases, $139(53.5 \%)$ were male patients while $121(46.5 \%)$ were female patients. A study conducted in Kenya by Alaro et al ${ }^{12}$ has also reported $60 \%$ male gender predominance which is close to our study results. A study conducted by Medani et al ${ }^{13}$ from Sudan has also reported $59 \%$ male gender predominance which is similar to that of our study results. A study conducted by Chishty et al ${ }^{14}$ has also reported male gender predominance with 2.6:1 male to female gender ratio which is in compliance with our study results. A study conducted by Malik et al ${ }^{15}$ has also reported $78 \%$ male gender predominance which is close to our study results. A study conducted by Afzal et al ${ }^{16}$ has also reported $60 \%$ male gender predominance which is in compliance with our study results.

Mean age of our study cases was $3.84 \pm 1.47$ hours (with minimum age of our study cases was 1 hour while maximum age was 6 hours). Mean age of the male patients was noted to be $3.61 \pm 1.03$ hours while that female patients was $2.96 \pm 1.28$ hours $(\mathrm{p}=0.531)$. Our study results have indicated that majority of our study cases i.e. $165(63.5 \%)$ were aged up to 3 hours. A study conducted by Medani et al ${ }^{13}$ from Sudan has also reported similar results. A study conducted in Kenya by Alaro et al ${ }^{12}$ has also reported similar results. A study conducted by Chishty et al ${ }^{14}$ has also reported $75 \%$ cases were aged up to 24 hours of birth which is different from our study results, however our patients were all registered within first 6 hours as per our inclusion criteria/methodology. Of these 260 study cases, 177 (68.1\%) belonged to rural areas and $83(31.9 \%)$ belonged to urban areas. Monthly family income up to Rs. 35000 was noted in 151 (58.1\%) and more than Rs. 35000 was noted in $109(41.9 \%)$ in our study cases. Of these 260 study cases, home delivery was noted in $91(35.0 \%), 149$ $(57.3 \%)$ in private clinics / hospital and $20(7.7 \%)$ in teaching hospital. Vaginal deliveries were noted 179 $(68.8 \%)$ while cesarean section deliveries were noted in 81 (31.2\%). A study conducted by Medani et al ${ }^{13}$ from Sudan has also reported similar results. A study conducted in Kenya by Alaro et al ${ }^{12}$ has also reported similar results. A study conducted by Chishty et al ${ }^{14}$ has also reported $23 \%$ birth asphyxia newborns were born at Government hospitals which is close to our study results. A study conducted by Malik et al ${ }^{15}$ has also reported similar results. A study conducted by Medani et al ${ }^{13}$ from Sudan has also reported $56.4 \%$ vaginal deliveries which is close to our study results. A study conducted in Kenya by Alaro et al ${ }^{12}$ has also reported $33 \%$ cesarean section deliveries which is in compliance with our study results. A study conducted by Chishty et al ${ }^{14}$ reported only $16 \%$ cesarean section deliveries in these patients which is quite lower than our study results. A study conducted by Afzal et al ${ }^{16}$ has also reported $33 \%$ cesarean section deliveries which is close to our study results.

Mean gestational age of our study cases was $38.23 \pm 2.38$ and preterm births were noted in $91(35.0 \%)$ of our study cases. A study conducted by Chishty et al ${ }^{14}$ has also reported 39.18 weeks mean gestational age which is similar to that of our study results. A study conducted by Afzal et al ${ }^{16}$ has also reported $27 \%$ preterm births which is in compliance with our study results.

Of these 260 study cases, control of fits were noted in $173(66.5 \%)$ while control of fits in group A control of fits were noted in $105(80.8 \%)$ and in group B it was $68(52.3 \%)(\mathrm{p}=0.000)$. A study from Sri Lanka ${ }^{11}$ has reported MgSO4 was effective in controlling of fits as fits were observed in $18.5 \%$ (continued for 24 hours) in treated neonates having birth asyphyxia while control group (without MgSO4) exhibited more fits 34.4\%. These findings are in compliance with our study.

\section{CONCLUSION;}

Our study results support the use of Magnesium Sulphate in control of fits in children with birth asphyxia. Magnesium sulphate was safe, reliable and having no side effect so it can be used safely in these patients to reduce morbidity and mortality. All clinicians treating such patients can employ this treatment modality having safety and efficacy.

\section{REFERENCES:}

1. Aslam HM, Saleem S, Afzal R, Iqbal U, Saleem SM, Shaikh MW, et al. Risk factors of birth asphyxia". Ital J Pediatr. 2014 Dec 20;40:94. doi: 10.1186/s13052-014-0094-2.

2. Boskabadi $\mathrm{H}^{1}$, Ashrafzadeh $\mathrm{F}^{1}$, Doosti $\mathrm{H}^{2}$, Zakerihamidi $\mathrm{M}^{3}$. Assessment of risk factors and prognosis in asphyxiated infants. Iran J Pediatr. 2015 Aug;25(4):e2006. doi: 10.5812/ijp.2006. Epub 2015 Aug 24.

3. Chiabi $\mathrm{A}^{1}$, Nguefack $\mathrm{S}^{1}$, Mah $\mathrm{E}^{1}$, Nodem $\mathrm{S}^{2}$, Mbuagbaw $\mathrm{L}^{3}$, Mbonda $\mathrm{E}^{1}$, et al. Risk factors for birth asphyxia in an urban health facility in Cameroon. Iran J Child Neurol. 2013;7(3):46-54.

4. Geva A, Gray J. A quantitative analysis of optimal treatment capacity for perinatal asphyxia. Med Decis Making. 2012;32(2):266-72. 
5. Majeed R, Memon Y, Majeed F, et al. Risk factor of birth asphyxia. J Ayub Med Coll Abbottabad . 2007;19(3):67-71.

6. Butt TK, Farooqui R, Khan MA. Risk factors for hypoxic encephlopathy in children. J Coll Physicians SurgPak. 2008;18(7):428-32.

7. Nauman Kiyani $\mathrm{A}^{1}$, Khushdil $\mathrm{A}^{1}$, Ehsan $\mathrm{A}^{1}$.Perinatal factors leading to birth asphyxia among term newborns in a tertiary care hospital. Iran J Pediatr. 2014 Oct;24(5):637-42.

8. Doll E ${ }^{1}$, Wilkes $\mathrm{J}^{2}$, Cook $\mathrm{LJ}^{3}$, Korgenski EK ${ }^{2}$, Faix $\mathrm{RG}^{4}$, Yoder $\mathrm{BA}^{4}$, et al. Neonatal magnesium levels correlate with motor outcomes in premature infants: a long-term retrospective cohort study. Front Pediatr. 2014 Nov 5;2:120. doi: 10.3389/fped.2014.00120.

9. Ostrander $\mathrm{B}^{1}$, Bardsley $\mathrm{T}^{2}$, Korgenski $\mathrm{EK}^{3}$, Greene $\mathrm{T}^{2}$, Bonkowsky $\mathrm{JL}^{4}$. Neonatal magnesium levels between 24 and 48 hours of life and outcomes for epilepsy and motor impairment in premature infants. Pediatr Neurol. 2016 Jun;59:41-6.

10. Gathwala $G^{1}$, Khera A, Singh J, Balhara B. Magnesium for neuroprotection in birth asphyxia. J Pediatr Neurosci. 2010 Jul;5(2):102-4. doi: 10.4103/1817-1745.76094.

11. Sreenivasa B, Lockeshwari K, Joseph N. Role of magnesium sulphate in the management and prevention of short term complications of birth asphyxia. Sri Lanka J Child Health. 2017;46(2):148-51

12. Alaro D, Bashir A, Musoke R, Wanaiana L. Prevalence and outcomes of acute kidney injury in term neonates with perinatal asphyxia. Afr Health Sci. 2014;14(3):682-8.

13. Medani $\mathrm{SA}^{1}, \mathrm{Kheir} \mathrm{AE}^{2}$, Mohamed $\mathrm{MB}^{3}$. Acute kidney injury in asphyxiated neonates admitted to a tertiary neonatal unit in Sudan. Sudan J Paediatr. 2014;14(2):29-34.

14. Chishty AL, Iqbal MA, Anjum A, Maqbool S. Risk factor analysis of birth asphyxia at the children`s hospital, Lahore. Pak Paed J. 2002;26(2):47-53.

15. Malik TS, Chishti AL, Ahmed TM. Short term Neurodevelopmental outcome of asphyxiated newborns at tertiary care unit. Pak Paed J. 2007;31(2):58-61. 